\title{
PENEGAKAN HUKUM TERHADAP ILLEGAL DRILLING
}

\author{
Ivan Fauzani Raharja1, Eko Nuriyatman ${ }^{2}$ \\ ${ }^{1}$ Program Khusus Hukum Administrasi Negara Fakultas Hukum Universitas Jambi, \\ ${ }^{2}$ Pengamat Kebijakan Hukum Lingkungan \\ Jl. Raya Jambi - Ma. Bulian Km. 15 \\ Email: ivanfauzani_fh@unja.ac.id, ekonuriyatman90@gmail.com
}

\begin{abstract}
This scientific article examines law enforcement against illegal drilling activities that are rife in the Village of Pompa Air and the Bungku Village, Kecamatan Bajubang District, Kabupaten Batanghari, Provinsi Jambi. The oil sector is a sector that makes this sector vulnerable to various crimes, oil theft occurs almost every day in three modes, namely illegal tapping, illegal drilling and misuse of subsidized fuel. The activity of oil theft through illegal drilling seems to be an endless story, especially for the people of Bajubang District, Batanghari District, since 2017 there have been four cases and in 2018 there were nine cases with 31 suspects all of whom were prosecuted by the Law of the Republic of Indonesia Number 22 of 2001 concerning Oil and Gas with demands of four years to six years in prison and a fine of 60 billion Rupiah. The research method used in this scientific article is a nondoctrinal (empirical) research method. Based on the results of field research on law enforcement against illegal drilling, it was concluded that law enforcement against illegal linin activities has not been carried out optimally because there is no strong legal umbrella owned by the regional government because the authority to handle the control of illegal activities is the authority of the central government.
\end{abstract}

Keywords; Natural Resources, Illegal Driling, Law Enforcement.

\begin{abstract}
Abstrak
Artikel ilmiah ini meneliti mengenai penegakan hukum terhadap kegiatan illegal drilling yang marak terjadi pada Desa Pompa Air dan Desa Bungku Kecamatan Bajubang Kabupaten Batanghari Provinsi Jambi. Sektor minyak merupakan sektor yang sangat membuat sektor ini rentan akan berbagai tindak kejahatan, pencurian minyak terjadi hampir setiap hari dalam tiga modus yaitu illegal tapping, illegal drilling dan penyelewengan bahan bakar minyak (BBM) bersubsidi. Kegiatan pencurian minyak melalui illegal drilling seakan menjadi cerita yang tidak berkesudahan khususnya untuk masyarakat Kecamatan Bajubang Kabupaten Batanghari, semenjak tahun 2017 sudah terdapat empat kasus dan pada tahun 2018 terdapat sembilan kasus dengan 31 orang tersangka yang mana semua di tuntut dengan Undang-Undang Republik Indondesia Nomor 22 Tahun 2001 Tentang Minyak dan Gas Bumi dengan tuntutan empat tahun sampai dengan enam tahun penjara dan denda sebesar 60 Milyar Rupiah. Metode penelitian yang digunakan dalam artikel ilmuah ini adalah metode penelitian nondoktrinal (empiris). Berdasarkan hasil penelitian dilapangan terhadap penegakan hukum terhadap illegal drilling didapat kesimpulan bahwa penegakan hukum terhadap kegiatan illegal linin belum dilaksanakan sevara optimal dikarenakan belum ada payung hukum yang kuat
\end{abstract}


dimiliki oleh pemerintah daerah karena kewenangan untuk menangani penertiban dari kegiatan illegal tersebut merupakan wewenang dari pemerintah pusat.

Kata Kunci; Sumber Daya Alam, Illegal Driling, Penegakan Hukum.

\section{PENDAHULUAN}

Undang-Undang Dasar Negara Republik Indonesia Tahun 1945 pada Pasal 33 ayat (3) berbunyi "Bumi dan air dan kekayaan alam yang terkandung di dalamnya dikuasai oleh Negara dan dipergunakan untuk sebesar-besar kemakmuran rakyat," berdasarkan isi pasal tersebut dapat disimpulkan bahwa dalam hal ini minyak dan gas bumi adalah salah satu kekayaan alam dari hasil pertambangan yang mempunyai nilai sangat strategis bagi kehidupan bangsa Indonesia sebagai sumber energi dalam negeri, sumber penerimaan negara, maupun sebagai bahan baku industri petrokimia dan lainnya. Pada saat ini perekonomian dunia sangat bergantung dengan ketersediaan minyak karena itu, tidak mengherankan bila negara saling berlomba mengeksplorasi sumber daya alam (SDA) ini.

Sektor minyak merupakan sektor yang sangat membuat sektor ini rentan akan berbagai tindak kejahatan. Adapun masalah yang sering terjadi antara lain, monopoli harga minyak, pembajakan dalam pendistribusian, pencurian minyak, penambangan ilegal, penyelundupan minyak. Pencurian minyak merupakan salah satu masalah yang tingkat urgensinya sangat tinggi. Selain itu, pencurian minyak terjadi hampir setiap hari dalam tiga modus yaitu illegal tapping, illegal drilling dan penyelewengan bahan bakar minyak (BBM) bersubsidi. Implementasi komitmen perusahaan dalam menjaga keberlanjutan lingkungan pada setiap proyek pengembangan panas bumi yang dikerjakan, haruslah berpedoman dan telah dilengkapi dengan Analisis Mengenai Dampak Lingkungan (Amdal), Rencana Pengelolaan Lingkungan (RKL) dan Rencana Pemantauan Lingkungan (RPL) sesuai dengan ketentuan yang berlaku dan senantiasa mengacu kepada Undang-Undang Republik Indonesia Nomor 32 Tahun 2009 tentang Perlindungan dan Pengelolaan Lingkungan Hidup.

Kegiatan pencurian minyak melalui illegal drilling seakan menjadi cerita yang tidak berkesudahan khususnya untuk masyarakat Kecamatan Bajubang Kabupaten Batanghari, yang mana terjadi dikarenakan kurangnya pengawasan oleh pemerintah 
dan kurangnya perhatian untuk dapat mengelola sumur tua yang ada di kecamatan tersebut. Sebenarnya Pengelolaan sumur tua sudah diatur melalui Peraturan Menteri Energi dan Sumber Daya Mineral Nomor 01 tahun 2008 tentang Pedoman Pengusahaan Pertambangan Minyak Bumi Pasa Sumur Tua. Namun yang terjadi saat ini adalah banyaknya tingkat pencurian minyak di kecamatan tersebut.

Banyak sekali dampak yang akan timbul akibat pengelolaan minyak bumi secara illegal drilling diantaranya yang terjadi kebakaran dan meledaknya sumur-sumur yang tidak dapat dikelola dengan baik oleh pelaku. Kegiatan illegal drilling tidak kalah bahayanya oleh karena itu harus ada regulasi yang dikeluarkan oleh Pemerintah Kabupaten Batanghari dan Pemerintah Provinsi Jambi untuk dapat mendorong sumur tua dimanfaatkan oleh masyarakat setempat dan menekan angka kemiskinan serta menambah pendapatan masyarakat sekitar.

Pada pengelolaan SDA pemerintah juga wajib melihat apa yang akan ditimbulkan atau dampak apa yang ada akibat adanya pengelolaan. Dampak merupakan "akibat lebih jauh pada masyarakat sebagai konsekuensinya dengan adanya kebijakan yang diimplementasikan."1 Namun perlu pula diperhatikan bahwa pada dimensi-dimensi dampak kebijakan yang sudah diimplementasikan oleh pemerintah perlu diperhatikan dampak kebijakan yang didampakkan dan dampak yang tidak diharapkan. Pada kejadian illegal drilig ini Pemerintah Kabupaten Batanghari secara tegas mengatasi kejadian tersebut dengan langsun turun kelokasi yaitu dengan "menutup sumur minyak ilegal di Desa Pompa Air, Kecamatan Bajubang," ${ }^{2}$ namun kegiatan ini mendapat perwalawan dari beberapa warga yang mana mereka merasa dirugikan.

Seharusnya masyarakpun memiliki kesadaran yang lebih tinggi lagi bahwa pencurian minyak dan pengeboran minyak ilegal merupakan aktifitas yang sangat berbahaya. Selain bisa merugikan pelaku juga berakibat kerusakan lingkungan. Dalam Peraturan Menteri Energi dan Sumber Daya Mineral Nomor 01 tahun 2008 tentang Pedoman Pengusahaan Pertambangan Minyak Bumi Pasa Sumur Tua telah ditegaskan bahwa pihak-pihak yang dapat mengelola pertambangan minyak bumi

\footnotetext{
122.

1 Subarsono AG. Analisis Kebijakan Publik Konsep, Teori dan Aplikasi. Yogyakarta: Pustaka Pelajar 2012, hlm.

2 Http://jambi.tribunnews.com/2019/01/30/tegas-melawan-illegal-drilling, diakses pada 14 Februari 2019, Pukul 08.00 Wib.
} 
pada sumur tua adalah kontraktor atau yang disini disebut Pertamina, kegaiatan usaha daerah (KUD) dan Badan Usaha Milik Daerah (BUMD), namun sepertinya pihak pertamina dan pemerintah kabupaten belum menanggapi hal tersebut dengan baik.

Padahal kegiatan illegal drilling sudah terlihat secara langsung di depan mata Bupati Kabupaten Batanghari Syahrial yang mana beliau menuturkan bahwa “aparatnya yang dinilai lamban dalam menyampaikan laporan, Dinas Lingkungan Hidup (DLH) Batanghari sebut hanya miskomunikasi."3 Aktifitas illegal drilling di Kecamatan Bajubang sudah sangat meluas sampai pada kawasan hutan lindung Taman Hutan Raya (Tahura) did aerah tersebut, hal ini menimbulkan dampak yang sangat buruk bagi lingkungan sekitar Tahura.

Semenjak Januari sampai dengan Oktober 2018 "Polda Jambi telah mengamankan dan menetapkan 18 orang tersangka terkait kasus aktivitas illegal drilling diwilayah Bajubang." ${ }^{4}$ Dari seluruh tersangka tersebut sudah ada yang P21 (lengkap), tetapi masih ada juga yang masih dalam proses penyidikan, pada setiap terjadinya penertiban terhadap aktifitas illegal drilling di Kecamatan Bajubang nyaris ricuh dikarenakan saat operasi masyarakat yang tertangkap mempertahankan peralatan yang mereka miliki.

Dampak dari kurangnya ketegasan pada pengelolaan penambangan minyak bumi ini membuat masyarakat lain (bukan pelaku) terkena imbas dari segi lingkungan yang tercemar. Meskipun sudah berulang kali aktifitas illegal driiling yang berlokasi di Kecamatan Bajubang ditutup, namun sepertinya penutupan tersebut tidak membuahkan hasil, bahkan aktifitas tersebut kian marak terjadi. Bahkan padahari Selasa 29 Januari 2019 tim gabungan dari Polres Batanghari, Pertamina, serta DLH dan Dinas Kesehatan Batanghari, melakukan penertiban terhadap lokasi illegal drilling di WKP, tepatnya di Desa Pompa Air, Kecamatan Bajubang.

Penertiban dilakukan sekira pukul 10.00 WIB. Dalam penertiban tersebut, tim gabungan mengerahkan dua unit alat berat jenis eskavator untuk melakukan penimbunan terhadap lokasi illegal drilling. Kepala Dinas Lingkungan Hidup (LH) Kabupaten Batanghari Parlaungan, SP mengatakan, pemberantasan terhadap

3 Http://jambi.tribunnews.com/2019/01/30/illegal-drilling-di-depan-mata-bupati-syahirsah-bawahandinilai-lamban-dinas-sebut-miskomunikasi, diakses pada 14 Februari 2019, Pukul 08.42 Wib.

$4 \mathrm{Https}$ ///infojambi.com/belasan-pelaku-pengeboran-minyak-ilegal-diamankan, diakses pada 14 Februari 2019, Pukul 09.12 Wib. 
aktivitas illegal drilling perlu peran serta semua pihak, termasuk pemerintah pusat. Jika hanya dibebankan kepada pemerintah daerah, Parlaungan mengaku tidak sanggup. "Kalau LH kabupaten tidak akan sanggup. Ini mesti dari pusat yang turun tangan," kata Parlaungan. Sesuai dengan kewenangan yang dimiliki, Parlaungan mengatakan pihaknya hanya melakukan pemantauan terhadap wilayah Tahura. Sementara, kata Parlaungan, pihaknya memperkirakan ada puluhan titik sumur illegal drilling di Batanghari. "Tadi saat kami ke lokasi, terdapat 50 lebih titik sumur illegal drilling yang kami temukan. Pasti masih banyak."

Lahirnya pemerintahan adalah untuk "menjaga suatu sistem ketertiban di dalam masyarakat, sehingga masyarakat tersebut bisa menyeleggaraka kehidupan secara wajar. Pemerintah pada era modern ini tidaklah ada untuk melayani diri sendiri, namun untuk melayani masyarakat serta menciptakan kondisi yang memungkinkan setiap anggota untuk dapat mengembangkan diri dan kreatifitas demi mencapai kemajuan bersama."6 Berdasarkan latar belakag diatas maka tim peneliti tertarik untuk melakukan penelitian mengenai illegal drilling di Kecamatan Bajubang Kabupaten Batanghari.

Penelitian ini termasuk kedalam penelitian nondoktrinal (empiris). Penelitian hukum nondoktrinal yang diteliti pada awalnya adalah "data sekunder untuk kemudian dilanjutkan dengan penelitian terhadap data primer di lapangan atau terhadap masyarakat,"7 dan peran dari pemerintah, provinsi, kabupaten dan dinas terkait. Penelitian nondoktrinal atau yang dikenal penelitian empiris atau sociolegal research "memandang hukum tidak terlihat sebagai realita sosial murni namun sebagai sistem nilai."8 Dalam penelitian ini tim penelitian turun langsung kelapangan untuk mengamati dan meneliti apa saja kendala dalam penegakan hukum terhadap illegal drilling di Kecamatan Bajubang Kabupaten Batanghari.

\footnotetext{
${ }^{5}$ Https://metrojambi.com/read/2019/01/29/39851/kadis-lh-batanghari-ngaku-tak-sanggup-berantasillegal-drilling, diakses pada 14 Februari 2019, Pukul 09.35 Wib.

6 Eko Nuriyatman. "Bagi Hasil Pertambangan Minyak Bumi Antara Pemerintah Pusat dan Pemerintah Daerah." Jurnal Selat, Mei 2019: Volume 6, Nomor 2, hlm. 185.

7 Soerjono Soekamto. Efektivikasi Hukum dan Peranan Sanksi. Jakarta: CV Remadja Karya, 1985, hlm. 52.

${ }^{8}$ Sulistyowati Irianto, dkk. Kajian Sosio-Legal. Jakarta: CV Remadja Karya, 2012, hlm. 5.
} 


\section{PEMBAHASAN}

Pada kegiatan penelitian mengenai illegal drilling ini peneliti melakukan wawancara dengan beberapa instansi yang terkait dengan penegakan hukum terhadap kegiatan yang dilarang oleh undang-undang ini. Berdaarkan hasil diskusi dan mewawancarai bagian penanganan illeal drilling, Parlaung, SP (Kepala Dinas Lingkungan Hidup) menyatakan bahwa aktifitas illegal drilling di Kabupaten Batanghari masih terus meningkat, bahkan saat ini aktifitas sudah merambah sampai pada Kawasan WKP EP-TAC PT.PBMSJ dan Kawasan Taman Hutan Raya (Tahura) Desa Bungku dan Desa Pompa Air, Kecamatan Bajubang.

Berdasarkan data yang didapat bahwa pada tanggal 28 Januari 2019 pada pukul 11.00 WIB, dua lokasi diatas telah disisir dan ditertibkan oleh Kepolisian Resort Polres Batanghari bersama Tim Terpadu. Penertiban tersebut langsung di pimpin oleh Kabagops Polres Batanghari Kompol Ahmad Bastari Yusuf. Dalam kegiatan penyisiran ini tidak tanggung-tanggung, jajaran pejabat utama Polres Batanghari hadir dalam penertiban tersebut, adapun jajaran pejabat tersebut, yaitu:

1. Kasat Saphara Polres Batanghari AKP H.Asrul Sani;

2. Kasat Intelkam AKP Tri Cahyono;

3. Kasat Reskrim AKP Dhadhag Anindito, S.IK;

4. Kasie Propam IPTU Heri Hermansyah;

5. Kapolsek Bajubang IPTU Elfian Yusran Ritonga; dan

6. Unsur dari Organsasi Perangkat Daerah (OPD) Terkait.

Kasat Intelkam Polres Batanghari AKP Tri Cahyono menuturkan bahwa pihak kepolisian Bersama tim lainnya melakukan penertiban terhadap lokasi illegal drilling yang masuk dalam Kawasan WKP. Setelah kegiatan tersebut dilakukan selanjutnya dilakukan pengambilan sample air limbah hasil aliran illegal drilling oleh Dinas Kesehatan dan DLH. Pihak Pertamina pun turut melakukan penutupan terhadap bak seler atau bak penampungan minyak hasil pengeboran secara illegal dengan menggunakan alat berat. Bak penampungan hasil minyak illegal yang ada di area WKP Pertamina EP-TAC PT.PBMSJ Desa Pompa Air Kecamatan Bajubang di tutup dengan menggunakan dua alat berat jenis ekskapator.

Pada saat terjadi razia gabungan oleh pihak Polda Jambi, Polres Batanghari, Polsek Bajubang dan unsur pimpinan daerah serta instansi daerah yang terkait 
penambangan minyak tanpa izin ini terdapat penolakan oleh warga yang menduduki daerah pertambangan minyak tersebut. Pada saat dilakukan penutupan menggunakan alat eskapator pada bak penampungan warga yang melakukan penambangan tanpa izin tersebut melakukan penghadangan dan mengatakan bahwa masyarakat memiliki sertifikat atas tanah yang dilakukan penggalian minyak illegal drilling tersebut yang sampai masuk pada area tambang pertamina.

Camat Bajubang Ikhwan saat dikonformasi mengatakan bahwa konflik tersebut sebenarnya terjadi akibat wilayah batas antara lahan milik warga dan pertamina belum ada kepastian secara jelas. Konflik tersebut terjadi karena tapal batas antara lahan milik warga dan wilayah kerja pertamina belum jelas. Ikhwan juga mengatakan bahwa pihaknya bahwa harus ada solusi yang terbit bagi masyarakat, agar tidak ada yang saling dirugikan.

Kegiatan yang terjadi pada dua desa di Kecamatan Bajubang yang beroperasi menghasilkan minyak-minyak mentah dari pengeboran sumur-sumur yang dikelola oleh masyarakat sekitar. Belakangan, aktifitas illegal drilling merambah hingga ke Tahura didalam hutan yang dikelola oleh pemerintah daerah dalam hal ini adalah DLH Kabupaten Batanghari, bahkan sudah terdapat ratusan dan ribuan sumur-sumur minyak ilegal.

Kegiatan illegal drilling yang dilakukan sejumlah oknum pada 2 (dua) desa di Kecamatan Bajubang Kabupaten Batanghari merupakan kegiatan yang mana merenggut kekayaan alam Jambi, yang mana akibat dari kegiatan ini adalag dapat merusak lingkungan serta terjadingan kebakaran bahkan ledakan pada sumur-sumur galian minyak tanpa izin tersebut. Meledaknya sumur galian minyak di ini disebabkan oleh adanya percikan api yang menyambar pada bak penampunyan yang berasal dari mesin robin yang terlampau panas dan menyebabkan minyak terbakar.

Mulanya kegiatan illegal drilling ini dilakukan pada lahan pribadi oleh warga dan beberapa oknum namun saat ini sudah sampai pada wilayah Tahura seluas $15.830 \mathrm{hk}$ yang mana sebagian wilayah ini sudah dirusak oleh penambang yang mana lokasi hutan ini tercemar oleh tumpahan minyak mentah dari kegiatan illegal tersebut.Pengelolaan minyak illeg al yang terus dilakukan secara terus menerus oleh masyarakat menimbulkan banyak kerugian di tengah-tengah masyarakat yang 
kontra akan tindakan llegal drilling tersebut yang mana dapat membahayakan hutan dan eksositem alam Kawasan Tahura.

Salah satu akibat dari kegiatan illegal drilling tersebut adalah terjadinya ledakan dan kebakaran pada sumur minyak di daerah Desa Pompa Air Kecamatan Bajubang terbakar pada hari Selasa pukul 11.00 Wib tanggal 13 Agustus 2019. Kebakaran tersebut bermula dari percikan api yang berasal dari mesin dompeng penyedot minyak, kemudian menjalar ke bak seler, sehingga menimbilkan ledakan api. Kapolsek Bajubang IPTU Alpian Ritonga mengatakan bahwa "sumur tersebut berlokasi diwilayah perkebunan kelapa sawit milik warga." ${ }^{9}$ Sekitar 15 menit kejadian langsung di padamkan oleh masyarakat sekitar, kemudian jumlah sumur illegal yang terbakar hanya satu. Alpian membeberkan untuk kasus tersebut harus di tangani oleh pihak Satreskrim Polres Batanghari, dalam kebakaran sumur galian illegal drilling ini tidak ada korban jiwa dan lokasi kejadian sudah di police line dan di amankan barang bukti berupa mesin penyedot, pipa paralon, canting besi.

Kejadian kebakaran dan ledakan pada galian illegal drilling tersebut pada tahun 2019 sudah terjadi sebanyak dua kali yaitu pada tanggal 18 Februari dan 12 Juni yang mana menewaskan pekerja atas nama Herda berumur 45 tahun. Bahkan pada bulan Februari 2019 pihak Polda Jambi AKP Sahlan (Kasubdit II Tipiter Ditreskrimsus Polda Jambi) berkerjasamana dengan Polres Batanghari dan Kapolsek Bajubang melakukan rasia dengan cara memutus mata rantai kegiatan illegal drilling tersebut denga menangkan 10 unit mobil pengangkut dengan total mintak bayat seberat 20 ton, pada daerah Tempino yang mana dari 10 unit monil tersebut ditangkap pula 10 pelaku yang memrupakan warga Sumatera Selatan yang mana berdasarkan pengakuan dari para pelaku harga satu drum minyak bayat tersebut saat dilakukan pembelian pada lokasi illegal drilling dengan harga Rp450.000,- per drum. Kesepuluh pelaku pengangkutan minyak illegal ini dijerat dengan Pasal 53 jo. Pasal 23 ayat 2 huruf b Undang-Undang Republik Indonesia Nomor 22 Tahun 2001 Tentang Minyak dan Gas Bumi dengan ancaman kurungan penjara selama 4 (empat) tahun penjara.

Praktik illegal drilling atau pengeboran minyak tak berizin semakin marak di beberapa daerah di Provinsi Jambi. Namun, ditengah ramainya kegiatan tersebut,

${ }_{9}$ Wawancara dengan Kapolsek Bajubang IPTU Alpian Ritonga. 
munculah sebuah wacana untuk melegalkan aktifitas tersebut. Parlauangan mengatakan "saya tidak bisa menjawab terkait hal itu, yang jelas segala sesuatu mengenai perizinan atau usulan itu harus ke kementerisn."10

Wacana pelegalan tersebut muncul pada Fokus Grup Discussion (FGD) atau Diskusi Kelompok Terkumpul (DKT) yang digelar oleh Polda Jambi dengan mengundang sejumlah pihak pada hari Jum'at tanggal 7 Mei 2019. Parlaungan enggan berkomentar banyak ketika dikonfirmasi masalah wacana pelegalan kegiatan tersebut. Meskipun pengelola Tahura adalah pemerintah daerah Parlaungan berpendapat bahwa "DLH harus memiliki izin dari kementerian untuk membuat rancangan teknis, penanaman pohon dan semacamnya." Jika belum memiliki izin dari kementerian pihak DLH belum bisa melakukan penanaman pohon di daerah tersebut. Parlaung menegaskan bahwa "terkait setuju atau tidak nya wacana tersebut memang harus langsung berhubungan dengan Kementerian Lingkungan Hidup.

Sepanjang tahun 2017 s.d tahun 2018 sudah terdapat beberapa kasus yang di tagani oleh pihak Kepolisian mengenai kegiatan illegal drilling, pada tahun 2017 terdapat 4 (empat) kasus dan pada tahun 2018 terdapat sebanyak 9 (sembilan) kasus dengan 31 tersangka. Menurut Brigjen Pol Ahmad Haydar selaku Wakapolda Jambi semua tersangka dituntut dengan denda 60 Milyar Rupian dengan dijerat Pasal 52 jo. Pasal 11 ayat 1 Undang-Undang Republik Indonesia Nomor 22 Tahun 2001 Tentang Minyak dan Gas Bumi.

Meskipun kegiatan illegal drilling ini sudah sering dirazia dan dilakukan penertiban oleh Polsek Bajubang, Polres Batanghari bahkan dari pihak Polda Jambi namun kejadian pengeboran minyak illegal ini terus saja berlangsung dan berkembang dengan pesat hal ini dkarenakan tidak ada instrument hukum yang kuat dalam hal pemberantasan kegiatan illegal drilling.

\section{PENUTUP}

\subsection{Simpulan}

Adapun kesimpulan pada artikel ilmiah ini adalah Pemerintah Provinsi Jambi dan pihak Keplolisian belumbisa melakukan optimalisasi penegakan hukum terhadap kegiatan illegal drilling dikarenakan belum ada payung hukum yang memberikan

\footnotetext{
10 Wawancara dengan Bapak Parlaungan Selaku Kepala Dinas Lingkungan Hidup Kabupaten Batanghari.
} 
kekuatan hukum tetap kepada pihak Kepolisian untuk melakukan penertiban praktek illegal drilling. Pihak Kepolisianpun belum memiliki anggaran yang cukup memadai untuk melakukan penertiban penutupan sumur tua yang disalahgunakan oleh warga/oknum yang melakukan kegiatan illegal drilling di Kecamatan Bajubang Desa Bungku dan Desa Pompa Air Kabupaten Muaro Batanghari Provinsi Jambi.

\subsection{Saran}

Adapun saran yang dapat peneliti berikan dalam artikel ini adalah sebaiknya pemerintah daerah dan kepolisian daerah segera berkoordinasi dengan pemerintah pusat dalam hal ini adalah Kementerian Lingkungan Hidup dan Kementerian ESDM agar dapat segera dibuatkan aturan/payung hukum yang kuat agar kegiatan illegal drilling ini dapat ditangani dengan baik karena kegiatan ini sudah merusak lingkungan dan ekosisten yang ada di dua desa Kecamatan Bajubang.

\section{DAFTAR PUSTAKA}

\section{A. Buku}

Soerjono Soekamto. Efektivikasi Hukum dan Peranan Sanksi. Jakarta: CV Remadja Karya, 1985.

Subarsono AG. Analisis Kebijakan Publik Konsep, Teori dan Aplikasi. Yogyakarta: Pustaka Pelajar 2012.

Sulistyowati Irianto, dkk. Kajian Sosio-Legal. Jakarta: CV Remadja Karya, 2012.

\section{B. Jurnal}

Eko Nuriyatman. "Bagi Hasil Pertambangan Minyak Bumi Antara Pemerintah Pusat dan Pemerintah Daerah.” Jurnal Selat, Mei 2019: Volume 6.

\section{Peraturan Perundang-Undangan}

Undang-Undang Negara Republik Indonesia Tahun 1945.

Undang-Undang Republik Indonesia Nomor 22 Tahun 2001 Tentang Minyak dan Gas Bumi

Undang-Undang Republik Indonesia Nomor 32 Tahun 2009 tentang Perlindungan dan Pengelolaan Lingkungan Hidup.

Peraturan Menteri Energi dan Sumber Daya Mineral Nomor 01 tahun 2008 tentang Pedoman Pengusahaan Pertambangan Minyak Bumi Pasa Sumur Tua 


\section{Sumber Lain}

Http://jambi.tribunnews.com/2019/01/30/tegas-melawan-illegal-drilling.

Http://jambi.tribunnews.com/2019/01/30/illegal-drilling-di-depan-mata-bupatisyahirsah-bawahan-dinilai-lamban-dinas-sebut-miskomunikasi.

Https://infojambi.com/belasan-pelaku-pengeboran-minyak-ilegal-diamankan.

Https://metrojambi.com/read/2019/01/29/39851/kadis-lh-batanghari-ngaku-taksanggup-berantas-illegal-drilling.

Wawancara dengan Kapolsek Bajubang IPTU Alpian Ritonga.

Wawancara dengan Bapak Parlaungan Selaku Kepala Dinas Lingkungan Hidup Kabupaten Batanghari. 